\title{
Inheritance of Tolerance to Verticillium albo-atrum in Raspberry
}

\author{
Joseph A. Fiola ${ }^{1}$ \\ Rutgers Fruit Research and Development Center, 283 Route 539, Cream \\ Ridge, NJ 08514 \\ Harry J. Swartz ${ }^{2}$ \\ Department of Horticulture, Holzapfel Hall, University of Maryland, College \\ Park, MD 20754
}

Additional index words. Rubus, raspberry breeding, disease resistance, Verticillium, wilts

\begin{abstract}
Raspberry cultivars and hybrids were screened for reaction to Verticillium alboatrum Reinke and Berth to determine the mode of inheritance of resistance and to assist in the development of resistant germplasm. Greenhouse-grown seedlings of an incomplete partial diallel of two black, purple, and red raspberry Rubus subgenus Idaeobatus progeny were root-dipped in a mycelial slurry and stem-inoculated with a conidial suspension of $V$. albo-atrum. Fourteen weeks after the initial inoculation, disease symptoms were observed in the seedlings. Disease symptom severity and percentage of black raspberry parentage in the seedlings were correlated $\left(P \leq 0.01 ; r^{2}=0.90\right)$. A similar significant $\left(P \leq 0.05 ; r^{2}=0.66\right)$ linear trend was found with fungus reisolation percentages, although isolation of the fungus from symptomless plants indicates Verticillium tolerance among genotypes in Idaeobatus. These trends, coupled with large significant general combining ability $(P \leq$ 0.01), suggest primarily additive inheritance of resistance. However, considering noninoculated control scores, the possibility of escapes, and skewing of populations, one may hypothesize a gene-gene model for symptom expression, with partial dominance of resistance alleles.
\end{abstract}

The fungus Verticillium albo-atrum causes a wilt that cannot be effectively controlled through chemical or cultural methods. In perennial crops, such as Rubus, the presence of this pathogen in planting sites is critical because establishment investment is great and $V$. albo-atrum is a soil inhabitant. The best means of control is an intrinsic genetic resistance similar to that in strawberry (Fragaria $\times$ ananassa Duch.)(Wilhelm, 1955) and solanaceous crops.

The disease reaction within Rubus ranges from extreme susceptibility ( $R$. occidentalis L.) to immunity ( $R$. procerus L.) (Wilhelm et al., 1965). Resistance to verticillium wilt in blackberry (subgenus: Eubatus) is dominant (Wilhelm et al., 1965; Wilhelm and Thomas, 1950). In raspberries (subgenus: Idaeobatus), black (R. occidentalis L.; R. leucodermis Torr.) and purple raspberries ( $R$. neglectus Peck.) are highly susceptible to verticillium wilt (Converse, 1966). Some resistance or tolerance occurs within the red raspberries (R. idaeus $\mathrm{L}$. varvulgatus; $R$. idaeus L. varstrigosus Michx.), although reactions may vary with pathogen biotypes and locations (Bennett, 1935; Vaughan and Rosenstiel, 1949). Our investigation was designed to determine the inheritance of verticillium wilt resistance in Idaeobatus.

Received for publication 27 Jan. 1994. Accepted for publication 27 Apr. 1994. The cost of publishing this paper was defrayed in part by the payment of page charges. Under postal regulations, this paper therefore must be hereby marked advertisement solely to indicate this fact.

${ }^{1}$ Specialist in Small Fruit and Viticulture.

${ }^{2}$ Associate Professor. for 2 months, and germinated in sphagnum under intermittent mist. Seedlings were transprogenies.

yercentage of black raspberry in background of progeny.

${ }^{\mathrm{w}} \mathrm{na}=$ no isolations attempted. planted to flats and later to 1-liter clay pots containing a steam-sterilized 3 peat : 1 sand : 1 heat-expandable shale (by volume) mix.

Verticillium preparation. Verticilliumalboatrum was isolated (Roberts and Broothroyd, 1972) from stem sections of infected black raspberry plants collected from the field. The fungus isolated was used to infect a "clean" susceptible black raspberry plant; after symptoms were induced, the fungus was reisolated. The fungus was cultured in $100 \times 15-\mathrm{mm}$ plastic petri plates containing potato dextrose agar with (mg.liter $\left.{ }^{-1}\right) 100$ vancomycin, 100 streptomycin, and 50 penicillin (PDA/A), and incubated at $22 \pm 3 \mathrm{C}$ under continuous light.

Plant screening. Seedlings with actively growing white root tips were broken out of the pots, the root ball was partially quartered to produce some damage, and the roots were dipped to the soil line in a fungal slurry. Mycelial-conidial inoculum for 14 plants was produced by blending nine plates of PDA/A containing actively growing $V$. albo-atrum in $500 \mathrm{ml}$ of distilled water for $7 \mathrm{sec}$. Seedlings were planted in seven $1 \times 3.3 \times 0.5$-m raised concrete tanks (blocks) containing a steamsterilized 15 peat : 3 expanded shale : 2 Manor loam soil (by volume) mix. Soil was maintained at $25 \pm 3 \mathrm{C}$ with heating cables, and photoperiod consisted of $24 \mathrm{~h}$ of continuous illumination through high-pressure emission lamps emitting $105 \mu \mathrm{mol} \cdot \mathrm{m}^{-2} \cdot \mathrm{s}^{-1}$ at plant level.

Eight weeks into the study, each seedling received a stem inoculation that involved inserting a piece of inoculum-soaked cotton inside a t-bud cut and wrapping with parafilm. A root inoculation was also performed to promote greater disease development, which consisted of pouring $100 \mathrm{ml}$ of the inoculum into a 1.5 -cm-diameter $\times 6$-cm-deep hole made with a cork borer into the soil and roots near the stem's base.

The design was a randomized complete

block (see Table 1 for seedling replication)

Table 1. List of crosses, percentage of black raspberry in genetic background, disease scores, fungal reisolation percentages, and numbers of individual seedlings for each cross included in the Verticillium resistance genetic analysis of an incomplete partial (six parents) diallel set of Rubus subgenus Idaeobatus

\begin{tabular}{|c|c|c|c|c|c|}
\hline \multicolumn{2}{|l|}{$\begin{array}{l}\text { Cultivar and/or } \\
\text { cross }^{z}\end{array}$} & $\begin{array}{c}\text { Black } \\
\text { raspberry } \\
(\%)^{\mathrm{y}}\end{array}$ & $\begin{array}{l}\text { No. } \\
\text { plants }\end{array}$ & $\begin{array}{c}\text { Mean } \\
\text { disease } \\
\text { score }^{x}\end{array}$ & $\begin{array}{c}\text { Verticillium } \\
\text { reisolated } \\
(\%)\end{array}$ \\
\hline \multicolumn{2}{|l|}{ Haut (br, parent) } & 100 & 14 & 3.3 & $\mathrm{na}^{\mathrm{w}}$ \\
\hline \multirow[t]{5}{*}{ Haut (br) } & x Jewel (br) & 100 & 28 & 4.0 & 50.0 \\
\hline & X Amethyst (pr) & 75 & 49 & 3.0 & 53.4 \\
\hline & x Royalty (rpr) & 62.5 & 49 & 2.8 & 32.3 \\
\hline & x Southland (rr) & 50 & 35 & 2.2 & 37.9 \\
\hline & x Willamette (rr) & 50 & 49 & 2.2 & 33.3 \\
\hline \multirow[t]{2}{*}{ Jewel (br) } & x Southland (rr) & 50 & 42 & 2.6 & 35.7 \\
\hline & x Willamette (rr) & 50 & 49 & 2.1 & 38.5 \\
\hline \multirow[t]{2}{*}{ Amethyst (pr) } & x Willamette (rr) & 25 & 49 & 2.0 & 37.5 \\
\hline & x Southland (rr) & 25 & 49 & 1.7 & 38.3 \\
\hline Willamette (rr) & x Southland (rr) & 0 & 49 & 1.8 & 37.5 \\
\hline \multicolumn{2}{|c|}{ Southland (rr, parent) } & 0 & 14 & 1.5 & na \\
\hline \multicolumn{2}{|c|}{ Willamette (rr, parent) } & 0 & 14 & 1.3 & na \\
\hline \multicolumn{2}{|c|}{ Noninoculated control } & --- & 70 & 1.7 & 0 \\
\hline
\end{tabular}

${ }^{\mathrm{z}} \mathrm{br}=$ black raspberry, $100 \%$ black raspberry; $\mathrm{pr}=$ purple raspberry, $50 \%$ black raspberry; $\mathrm{rpr}=$ red purple raspberry, $25 \%$ black raspberry; $\mathrm{rr}=$ red raspberry, $0 \%$ black raspberry.

${ }^{x}$ Mean disease score: 1 = no symptoms; 2 = slight leaf and/or stem lesion marginal necrosis; $3=$ more extensive necrosis, chlorosis, and death of leaves, with some stem lesions or blueing; 4 = extensive marginal necrosis with one-half of the leaves dead, and/or blue cane or stem lesions; $5=$ some or all canes dead. 
with six inoculated replications. A seventh $\%$ noninoculated block, which received all inoculation treatments (with no fungal inoculum), was planted for observation but not of included in the statistical analysis.

Data collection and analysis. Six weeks after the second inoculation, each seedling was given a subjective disease symptom rating based on the following scale: $1=$ no $\mathrm{P}$ symptoms; 2 = slight leaf and/or stem lesion u marginal necrosis; $3=$ more extensive necro- 1 sis, chlorosis, and death of leaves, with some stem lesions or blueing; 4 = extensive marginal necrosis with one-half of the leaves dead, and/or blue cane or stem lesions; $5=$ some or $i$ all canes dead. Systemic presence of the fungus was determined by taking four 1-mm cane cross-sections, $15 \mathrm{~cm}$ above the stem inoculation location, surface-sterilizing (same as isolation), and plating on PDA/A.

Disease score data were statistically analyzed using a computer program developed by Schaffer and Usanis (1969). F ratios, combining ability effects, and variances were calculated according to Griffing's method 4, model I analysis, for partial diallels with one set of $F_{1}$ progeny. Neither parents nor reciprocal $\mathrm{F}_{1} \mathrm{~s}$ were included (Griffing, 1956).

\section{Results}

Five weeks after the second set of inoculations, symptoms were evident on susceptible genotypes. Ten percent of the 'Haut' plants and susceptible $X$ susceptible crosses showed severe symptoms and died 14 weeks from the start of the experiment. The symptoms on hybrids with red raspberry in their background included less severe marginal necrosis with no stem blueing, and $19 \%$ of the seedlings were symptomless.

Seedlings with black raspberry parents or grandparents had the highest average disease scores (Table 1). A linear relationship existed between percent black raspberry in seedlings and average disease score [y (disease score) $=$ $0.02 x$ (percent black raspberry) $+1.46 ; P \leq$ $\left.0.01 ; r^{2}=0.90\right]$. No significant genotypic variation was observed in noninoculated controls (average disease score $=1.7$ ). Frequency distribution histograms show the spread of disease scores within hybrid populations (Fig. 1).

Verticillium was reisolated from $32 \%$ to $53 \%$ of the progeny (Table 1). The same significant linear trend [y (percent reisolation) $=0.15 \mathrm{x}$ (percent black raspberry) $+33.1 ; P \leq$ $\left.0.05 ; r^{2}=0.66\right]$ was observed, with reisolation percentages decreasing as the amount of black raspberry in the background decreased.

General combining ability (GCA) for disease score of the combined six parents was highly significant (Table 2). GCA for disease score for the complete partial diallel, including 'Haut', 'Jewel', 'Willamette', and 'Southland', was also highly significant (Table 2).

GCA estimates for black raspberry parentals were high positive values, with that for 'Haut' $(0.40)$ being slightly higher than for 'Jewel' (0.35). 'Willamette' $(-0.40)$ and 'Southland' (-0.35) had similar negative GCA estimates. Negative GCA values signify resis-

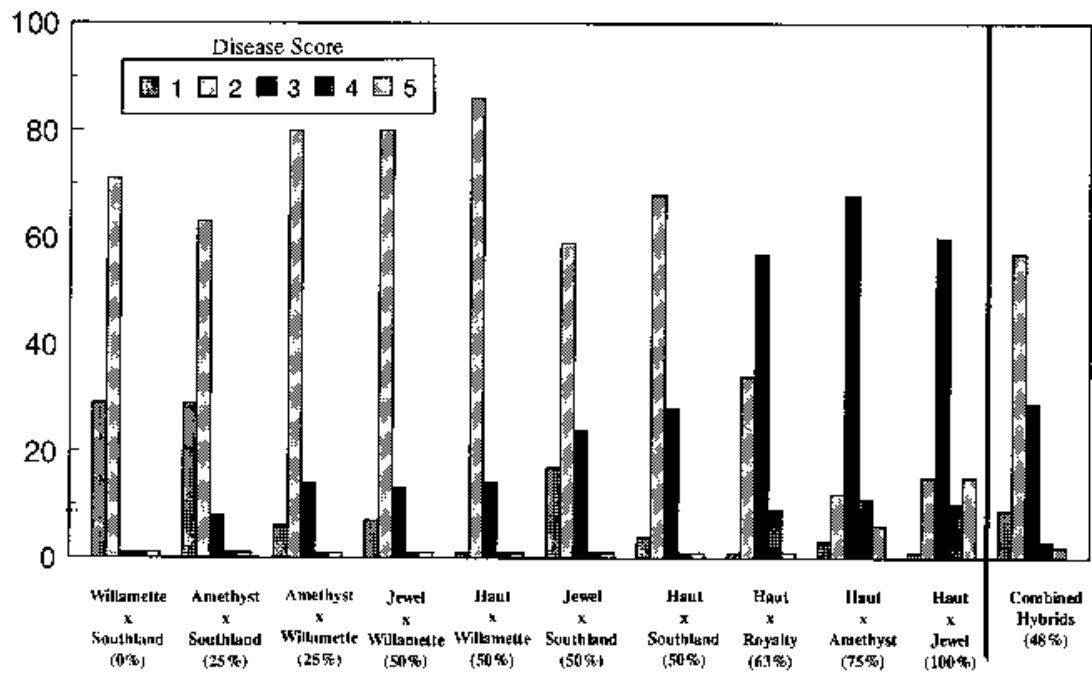

Hybrid Cross

(\% Black Raspberry of Scedling Population)

Fig. 1. Frequency histograms of percentages of populations vs. Verticillium disease scores in a genetic analysis of an incomplete partial (six parents) diallel sets of Rubus subgenus Idaeobatus progenies. Five columns of histogram denote disease score: 1 = no symptoms; 2 = slight leaf and/or stem lesion marginal necrosis; 3 = more extensive necrosis, chlorosis, and death of leaves, with some stem lesions or blueing; $4=$ extensive marginal necrosis with one-half of the leaves dead, and/or blue cane or stem lesions; $5=$ some or all canes dead.

tance, positive values, susceptibility, with the disease score scale used in this study.

\section{Discussion}

A Verticillium isolate was used successfully to incite disease symptoms on raspberry. In this experiment, symptoms induced through the cane inoculation technique appeared in 5 weeks as opposed to 3 to 4 weeks, as reported by Fulton (1952). Symptoms on black raspberry, especially cane discoloration, were much more severe than on red raspberry, as has been previously noted (Berkeley and Jackson, 1926; Converse, 1966). The Verticillium inoculum was lethal to some of the black raspberry genotypes, but not to the red raspberry hybrids. Black raspberry is extremely susceptible to Verticillium (Wilhelm et al., 1965), whereas some resistance or tolerance exists in red raspberry (Vaughan and Rosenstiel, 1949).

Bennett (1935) and Pratt (1957) reported that Verticillium can be isolated from symptomless red raspberry plants and that infected plants may appear to recover under certain environmental conditions. In this study, Verticillium was reisolated from all hybrids, independent of the presence of symptoms. Because the pathogen is actively entering and colonizing the host, but not causing obvious or extensive damage, it is more appropriate to consider the defense a tolerance rather than an actual resistance (Nelson, 1975).

Some limited marginal necrosis was observed on control plants. Although this appeared to be similar to a mild disease reaction, the symptoms were random, and no Verticillium was isolated from control plants. Thus, the symptoms were probably due to crowding and water stress due to increased water use of uninfected plants.
Although this test was not as severe as desired, apparent genotypic differences were obtained. Due to the limited number of parents involved (fixed model), and use of a single isolate of the pathogen, specific genetic inferences must be limited, although some general trends and effects may be observed. 'Willamette' $(-0.40)$ and 'Southland' $(-0.35)$ had similar negative GCA estimates, showing increased tolerance of red raspberries over black or purple raspberries. 'Southland's slightly lower GCA may be due to the contribution of $R$. parvifolius Nutt in its pedigree (Dale et al., 1993). Converse (1966) reported that red raspberry reaction to Verticillium is less severe than that of black raspberry. Although the disease reactions of $R$. idaeus cultivars can vary by location (Bennett, 1935; Vaughan and Rosenstiel, 1949), the red raspberry cultivars included passed on pathogen tolerance to their progeny under our experimental conditions.

Table 2. Analysis of variance of general combining ability (GCA) and specific combining ability (SCA) for Verticillium disease scores in an incomplete partial (six parents) and complete (four parents) diallel sets of Rubus subgenus Idaeobatus progenies.

\begin{tabular}{|c|c|c|c|}
\hline $\begin{array}{l}\text { Source of } \\
\text { variation }\end{array}$ & df & MS & $\mathrm{F}$ \\
\hline \multicolumn{4}{|c|}{ Incomplete partial (six parents) diallel } \\
\hline GCA & 5 & 11.65 & $27.10^{* *}$ \\
\hline SCA & 9 & 0.71 & $1.69^{\text {Ns }}$ \\
\hline Error & 273 & 0.43 & \\
\hline \multicolumn{4}{|c|}{ Complete partial (four parents) diallel } \\
\hline GCA & 3 & 8.04 & $17.87^{* *}$ \\
\hline SCA & 2 & 1.30 & $2.89^{\mathrm{Ns}}$ \\
\hline Error & 145 & 0.45 & \\
\hline
\end{tabular}


GCA estimates for black raspberry parentals were high positive values, with values for 'Haut' slightly higher than for 'Jewel', showing the general susceptibility of the black raspberry cultivars involved. This result again is consistent with reports of general susceptibility to Verticillium in black and purple raspberries (Converse, 1966; Wilhelm et al., 1965).

The large significant GCA component and the continuous linear variation between the black raspberry susceptible reaction and the red raspberry tolerant reaction suggests a primarily additive model of variation for Verticillium tolerance. This model would concur with inheritance models in strawberry (Bringhurst et al., 1967). However, considering noninoculated control scores of 1.7 , the possibility of escapes, and skewing of populations of $50 \%$ or less black raspberry toward the resistant (disease score $=1-2$ ), we hypothesize a genegene model for symptom expression, with partial dominance of resistance alleles. This hypothesis would concur with inheritance models in Eubatus (Wilhelm, 1955; Wilhelm and Thomas, 1950), as well as strawberry (Bringhurst et al., 1967).

Significant GCA effects show that genetic gains in verticillium wilt resistance may be attained in a recurrent breeding design. These genetic effects can be exploited since raspberries are vegetatively propagated.

\section{Literature Cited}

Bennett, C.W. 1935. Michigan raspberry diseases. Mich. Agr. Expt. Sta. Spec. Bul. 178

Berkeley, G.H. and A.B. Jackson. 1926. Verticillium wilt of the red raspberry. Sci. Agr. 6:261270.

Bringhurst, R.S., P.E. Hansche, and V. Voth. 1967. Inheritance of Verticillium wilt resistance and the correlation of resistance with performance traits of the strawberry. Proc. Amer. Soc. Hort. Sci. 92:369-375.

Converse, R.H. 1966. Diseases of raspberries and erect and trailing blackberries. U.S. Dept. Agr. Res. Serv. Hdbk. 310.

Dale, A., P.P. Moore, R.J. McNicol, T.M. Sjulin, and L.A. Burmistrov. 1993. Genetic diversity of red raspberry varieties throughout the world. J. Amer. Soc. Hort. Sci. 118:119-129.

Ellis, M., R.H Converse, R.N. Williams, and B. Williamson. 1991. Compendium of raspberry and blackberry diseases and insects. APS Press, St. Paul, Minn.

Fulton, R.H. 1952. Verticillium wilt of raspberries. Michigan Agr. Expt. Sta. Quarterly Bul. 25.

Griffing, B. 1956. Concept of general and specific combining ability in relation to diallel crossing systems. Austral. J. Biol. Sci. 9:463-493.

Nelson, R.R. 1975. Introduction, p. 3-12. In: R.R. Nelson (ed.). Breeding plants for disease resistance-Concepts and applications. Pennsylvania State Univ. Press, University Park.

Pratt, M.J. 1957. Occurrence, behavior, and control of Verticillium albo-atrum Reinke and Berth. in small fruits. Dis. Abstr. 18:36-37.

Roberts, D.A. and C.W. Broothroyd. 1972. Techniques for diagnosis, p. 356-359. In: D.A. Roberts and C.W. Broothroyd. Fundamentals of plant pathology. W.H. Freeman and Co., San Francisco.

Schaffer, H.E. and R.A. Usanis. 1969. General least squares analysis of diallel experiments: A computer program. North Carolina State Univ. Genet. Dept. Rpt. 1.

Vaughan, E.K. and R.G. Rosenstiel. 1949. Diseases and insect pests of cane fruits in Oregon. Oregon Agr. Expt. Sta. Bul. 418.

Wilhelm, S. 1955. Verticillium wilt of the strawberry with special reference to resistance. Phytopathology 45:387-391.

Wilhelm, S., R.S. Bringhurst, and V. Voth. 1965. Origins of Rubus cultivars resistant to Verticillium wilt. Phytopathology 35:731-733.

Wilhelm, S. and H.E. Thomas. 1950. Verticillium wilt of bramble fruits with special reference to Rubus ursinus derivatives. Phytopathology 40:1103-1110. 